\title{
Acoustic non-destructive testing of high temperature degraded concrete with comparison of acoustic impedance
}

\author{
Richard Dvoř́ák ${ }^{1, *}$, ZdeněkChobola ${ }^{1}$, and IvoKusák ${ }^{1}$ \\ ${ }^{1}$ Brno University of Technology, Faculty of Civil Engineering, Veveří 331/95, Brno, Czech Republic
}

\begin{abstract}
The paper is focused on non-destructive measurement of high temperature degraded concrete test specimens of three mixtures different by the use of coarse aggregate. Testing is done by ultrasonicpulse velocitymethod and Impact-Echo method. Non-destructive results are compared with destructive tests. Ultrasonic pulse velocity, dominant resonance frequency and acoustic impedance are discussed and compared with changes in density, cubic compressive strength, and tensile strength of concrete. The paper suggests possible assessment of degraded concrete by the change in acoustic impedance dependent on residual tensile strength.
\end{abstract}

\section{Introduction}

Acoustic non-destructive methods like Impact-Echo or ultrasound pulse velocity method can be used to determine the location and extent of flaws such as cracks delamination, voids, honeycombing and debonding in plain, reinforced and post tensioned concrete structures. It can be also used to determine the condition of structure, which has been degraded by different factors[1].

During the measurement by Impact-Echo method, a frequency spectrum is evaluated. In terms of condition assessment of test specimens, a resonance frequency of longitudinal, transverse, and torsional wave propagation is determined. The change in frequency spectrum makes it possible to distinguish a change in physical-mechanical properties.

Ultrasonic velocity pulse method is based on measuring the travel time of ultrasonic pulse through the test specimen and acquiring the shortest travel time for chosen test position of exciter and receiver. In terms of degraded plain concrete, where cracks and microcracks occur, and the material begin to be more fragile, the ultrasonic pulse travels longer path, as it is avoiding the air voids, cracks, and inhomogeneity. This leads to longer travel time of ultrasonic pulse.

The principles behind these methods lay in the theory of stress wave propagation in heterogenous solid materials.

\subsection{Stress wave propagation}

The impact-echo method belongs to stress wave propagation non-destructive methods based on the use of transient stress waves. A stress wave pulse is excited by mechanical impact introduced into a structure of test specimen. This pulse travels into the structure as 
dilatational (P) and distortional (S) waves and along the surface as a Rayleigh (R) wave as is shown at Fig.2. The $\mathrm{P}$ - and $\mathrm{S}$-waves propagate into the structure along spherical waveforms and are reflected by internal cracks, voids, interface between different mediums and by external boundaries of the structure. A P-wave is associated with normal stress, while an S-wave is associated with shear stiffness. A Rayleigh wave, also called a surface wave or R-wave, propagates along the surface of a solid, and particle motion is retrograde elliptical[2].

Fig 1shows a situation when a P- or S-wave front is incident on a boundary between dissimilar media, "specular" reflection occurs. At a boundary between two different media only a portion of a stress wave is reflected. The remainder penetrates the underlying medium (wave refraction). The angle of refraction, $\beta$, is a function of the angle of incidence, $\theta$, and the ratio of wave speed, $\mathrm{C}_{2} / \mathrm{C}_{1}$, in the different media, and is given by Snell's Law. Depending on the angle of incidence, a P-wave can be partially reflected as both $\mathrm{P}$ - and S-waves and can be refracted as both P- and S- waves[3].

$$
R_{n}=\frac{Z_{2}-Z_{1}}{Z_{2}+Z_{1}}
$$

The portion of an incident ray of a $\mathrm{P}$-wave that is reflected at an interface between two media depends on the specific acoustic impedances of each medium (equation 1).
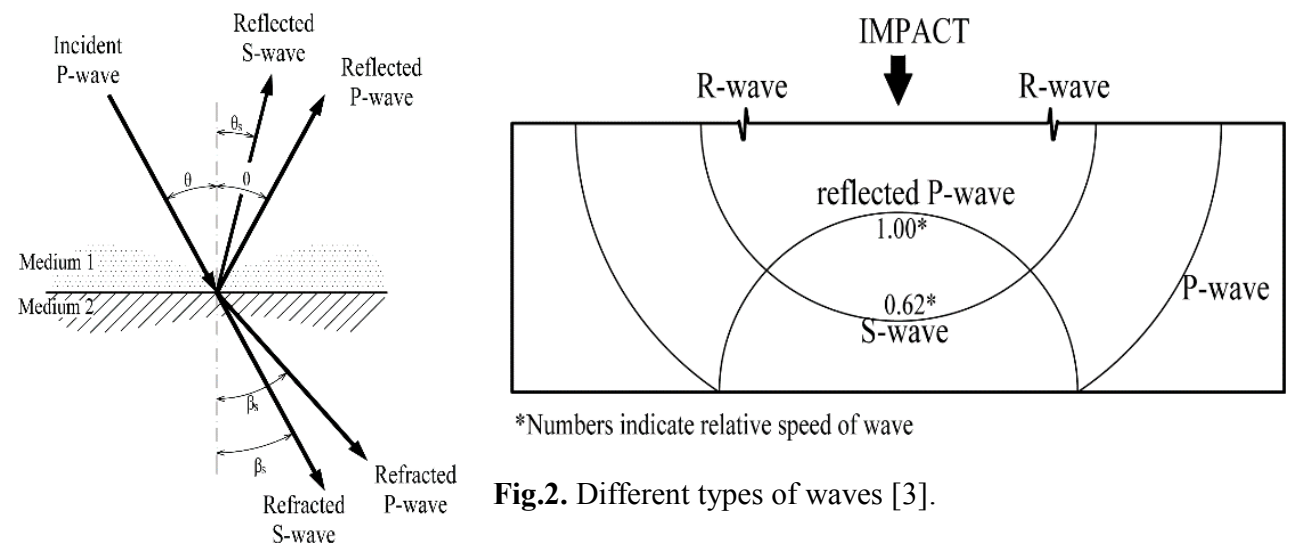

*Numbers indicate relative speed of wave

Fig.2. Different types of waves [3].

Fig 1. Reflection and refraction

of P-wave [3].

If mechanical wave propagating through concrete (concrete have acoustic impedance 9$10 \cdot 10^{6} \mathrm{~kg} \cdot \mathrm{m}^{-2} \cdot \mathrm{s}$ ) hit interface with air void (air have acoustic impedance $0.413 \mathrm{~kg} \cdot \mathrm{m}^{-2} \cdot \mathrm{s}$ ), mechanical wave is reflected and serve as new source of longitudinal, transverse andRayleigh waves.

$$
Z=D \cdot v_{L}
$$

The acoustic impedance of a material $Z$ is density $D$ multiplied by acoustic velocity $v_{L}$ in material. This parameter therefore combines the change in two material attributes, which are genuinely affected by high temperature.

\subsection{Degradation of concrete}

Concrete is a heterogenous material, which consists of fine and coarse aggregate, cement adhesive, additives, and mix water. Each compound reacts to elevated temperature 
differently, therefore the changes in physical-mechanical and physical-chemical properties cause a synergistic effect.

Consequently,we can divide the process of concrete degradation by high temperature by reaction of aggregate, cement matrix and free and bounded water content.

\subsubsection{Aggregate}

Aggregates with a high content of silica suffers to phase change of quartz at $574^{\circ} \mathrm{C}$ when $\beta$ quartz transform to $\alpha$-quartz. Approximately at $300-400^{\circ} \mathrm{C}$ silica aggregate begins to form microcracks at interface with cement matrix, which leads to increased porosity and absorption[4].

Limestone aggregate is slightly less resistant to high temperatures, but the decrease in strength for silica and limestone aggregate is more alike up to $700^{\circ} \mathrm{C}$. From this temperature a limestone aggregates have shown better performance, thanks to decomposition of calcite $\mathrm{CaCO}_{3} \rightarrow \mathrm{CaO}+\mathrm{CO}_{2}{ }^{\uparrow}$. Exceeding a threshold of $900^{\circ} \mathrm{C}$ both limestone and silica aggregate perform similar in term of residual strength[4].

\subsubsection{Cement}

The reaction of hydraulic cement binder to elevated temperature was thoroughly researched in past decades. The degradation process of cement matrix consists of two main compounds, $\mathrm{CSH}$ gels and portlandite $\mathrm{Ca}(\mathrm{OH})_{2}$. Dehydration of $\mathrm{CSH}$ gels take place in temperature range of 105 to $1000^{\circ} \mathrm{C}$ and consists of multi-step reaction. Portlandite dehydrate in temperature range from 400 to $550^{\circ} \mathrm{C}[5]$. Due to volume change during dehydration, the cement tends to shrink and form microcracks.

\subsection{Applied materials}

For the sake of an experiment a set of 3 mixtures A, B and C was designed. A number of 63 test specimens of diameter $100 \times 100 \times 400 \mathrm{~mm}$ were manufactured from each mixture. All teste specimens were stored in water containment for 28 days. Test specimens were afterwards preheated in laboratory oven at $110^{\circ} \mathrm{C}$ for 78 hours. By this, we remove residual free water content to prevent concrete from explosive spalling[6].

The mixture was prepared with use of fine aggregate of fraction $0 / 4 \mathrm{~mm}$ from local quarry Žabčice was and coarse aggregate of fraction $8 / 16 \mathrm{~mm}$ and 11/22 $\mathrm{mm}$ from local quarry Olbramovice. The applied fine aggregate mainly consist of quartz and coarse aggregate mainly consist of granodiorite, where the main compounds are feldspar, quartz, and biotite.Portland cement used in experiment was CEM I 42.5 R from local cement works Mokrá. Specific amounts of each compounds are shown inTable 1.

Table 1. Mixture designs.

\begin{tabular}{|l|c|c|c|}
\hline \multirow{2}{*}{ Compounds } & \multicolumn{3}{|c|}{ Amount of each compound for $\mathbf{~ m}^{\mathbf{3}}[\mathbf{k g}]$} \\
\cline { 2 - 4 } & Mixture A & Mixture B & Mixture C \\
\hline Cement CEM I 42.5 R & 345 & 345 & 345 \\
\hline Fine aggregate Žabčice 0/4 mm & 848 & 896 & 813 \\
\hline Coarse aggregate Olbramovice 4/8 mm & - & - & 1010 \\
\hline Coarse aggregate Olbramovice $8 / 16 \mathrm{~mm}$ & 980 & 521 & - \\
\hline Coarse aggregate Olbramovice 11/22 mm & - & 391 & - \\
\hline SuperplastizerSicaViscocrete 2030 & 2.8 & 2.5 & 3.1 \\
\hline Mix water & 160 & 173 & 176 \\
\hline
\end{tabular}


Test specimens were then fired in ceramics furnace Rhode KE 130B (shown at Fig.3)with temperature gain of $5^{\circ} \mathrm{C} / \mathrm{min}$. The aimed temperatures were maintained for 1 hour, the test specimens were spontaneously cooled to room temperature inside the furnace. Each mixture was divided to 1 reference set and 6 temperature fired sets. The reference set was kept at laboratory conditions at relative humidity of $50-60 \%$ and air temperature 19 $21^{\circ} \mathrm{C}$. After firing in the furnace, specimens were moved to laboratory conditions resembling the ones for a reference set.

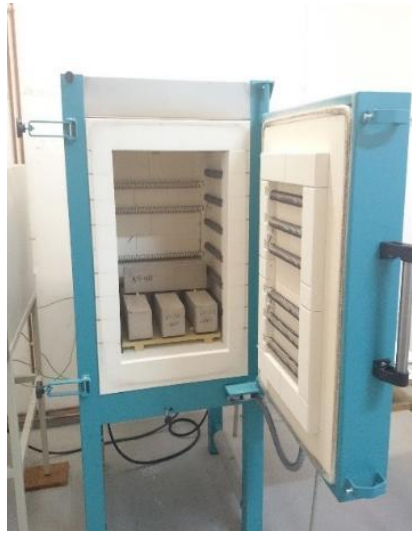

Fig.3. Ceramic furnance Rhode KE 130 B.

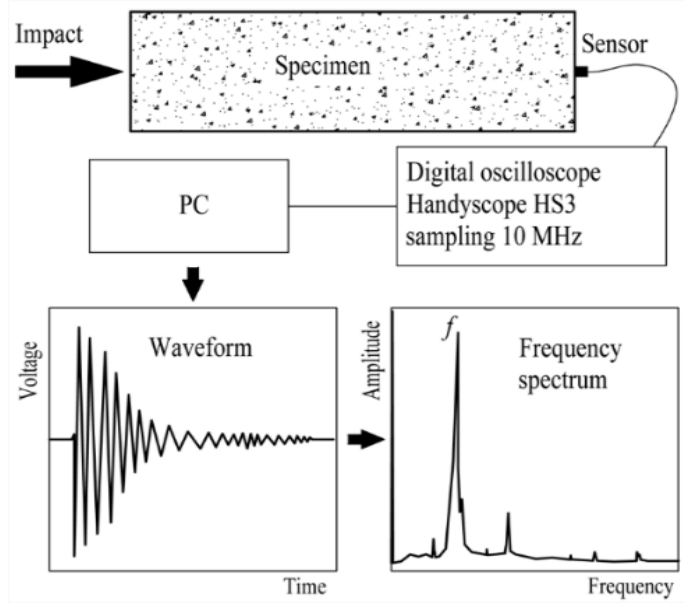

Fig.4. Impact-Echo test setup.

\subsection{Used methods}

\subsubsection{Ultrasound pulse velocity method}

The ultrasonic pulse analyser 58-E4900 was applied for the measurement. Measurement by ultrasonic pulse method was conducted in longitudinal way of test specimens laying on rubber pads. In order to determine the shortest time needed for ultrasonic pulse to travel the length of test specimen each test consists of three test positions of exciter and receiver. The first position is at centre of upper surface, second at the middle and third at centre of the specimen base. Three different travel speeds were acquired and the shortest was picked $\operatorname{as} v_{L}[7]$.

\subsubsection{Impact-Echo}

Measurement by Impact echo was conducted on test specimens placed on rubber pads. As exciter of mechanical stress waves a spherical hammer of a total mass $70.5 \mathrm{~g}$ was used. In order to perform vibration a piezoelectric sensor MIDI 446s12 was used, signal processing was performed by the use of digital oscilloscope Handyscope HS3 with sampling speed set to $0.2 \mathrm{MHz}$.In order to record the longitudinal waves, the receiver was placed in the front of test beam and exciter hit the test specimen at the opposite side [8].The measured signal was transformed to frequency spectrom by Fourier fast transformation [9].The measurement procedure is shown on Fig.4. Each recorded signal lasted $335 \mathrm{~ms}$ and was made up by 65.5 thousands records. Due toRAM memory instalation in the oscyloscope, each signal also contained first $3 \mathrm{~ms}$ of signal before the impact of mechanical impuls. 


\subsubsection{Destructive tests}

In order to compare the non-destructive results obtained by ultrasound pulse velocity method and Impact-Echo method destructive tests were conducted. The test specimens were tested by four-point bending test on flexural tensile strength[10] on each end of broken specimens a cubic compressive strength test was made[11].

\section{Results of measurement}

\subsection{Density and absorbance}

Test specimens have shown a slight loss of mass for thermally degraded test specimens as is shown atFig.5. The average density of non-degraded concrete specimens was for mixture A $2360 \mathrm{~kg} \cdot \mathrm{m}^{-3}$, for mixture B $2380 \mathrm{~kg} \cdot \mathrm{m}^{-3}$ and for mixture C $2210 \mathrm{~kg} \cdot \mathrm{m}^{-3}$. Density of mixture A lost $7.6 \%$ for set degraded by $1000^{\circ} \mathrm{C}$. This decrease in density was for mixture A lowest from all sets, mixture $\mathrm{B}$ lost $8.8 \%$ and mixture $\mathrm{C}$ nearly $9 \%$. Highest decrease of mass appeared between 20 and $200^{\circ} \mathrm{C}$ for mixture $\mathrm{B}$ and $\mathrm{C}$. This leap is due to pre-drying in laboratory oven of mixture B and C. Temperature sets of 200 and $400^{\circ} \mathrm{C}$ of Mixture A has not been pre-dried in the beginning of the experiment.

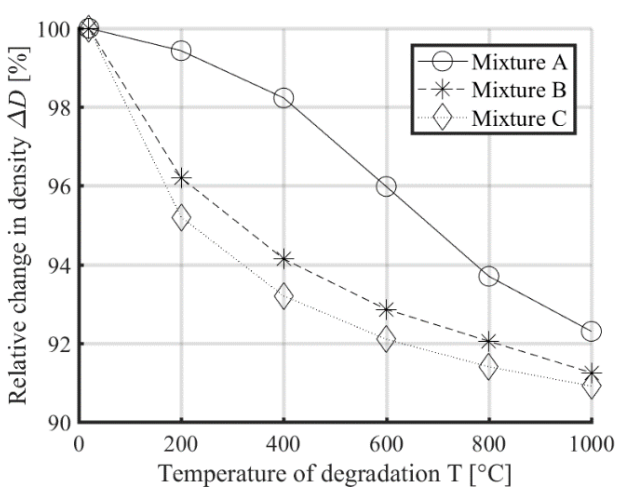

Fig.5. Relative change in density.

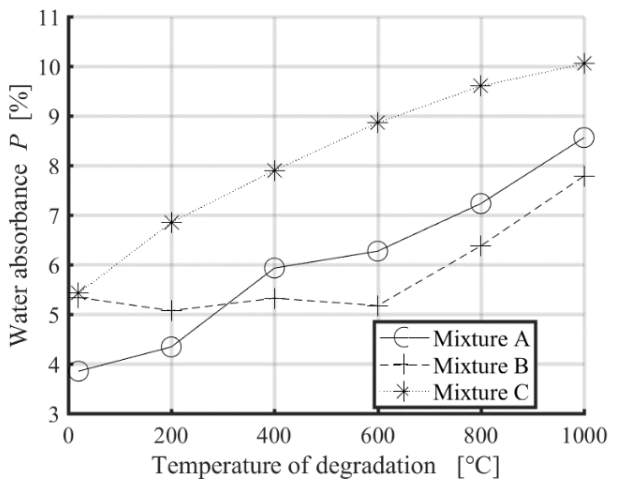

Fig.6. Change of water absorbance.

As mentioned in chapter 1.2, thermal degradation of concrete leads to the increase in porosity.Fig.6shows the results of water absorbance based on Czech norm for measurement of water absorbance and leakage of concrete[12]. Water absorbance of non-degraded specimens was equal $3.8 \%$ for mixture $\mathrm{A}, 5.2 \%$ for mixture $\mathrm{B}$ and 5.3 for mixture $\mathrm{C}$. The highest water absorbance $10 \%$ was detected for mixture $\mathrm{C}$ at a $1000^{\circ} \mathrm{C}$ set.

\subsection{Impact echo and ultrasonic pulse velocity measurement}

The measurement by Impact-Echo method has shown a change in dominant frequency spectrum (Fig.7.). The reference set showed frequency $5.22 \mathrm{kHz}$ for mixture A, $5.41 \mathrm{kHz}$ for mixture $\mathrm{B}$ and $4.92 \mathrm{kHz}$ for mixture $\mathrm{C}$. The first decrease in dominant frequency has appeared at temperature $400^{\circ} \mathrm{C}$ for mixture A. This change is due to the pre-drying of test specimens of mixture $\mathrm{B}$ and $\mathrm{C}$. The highest decrease in longitudinal frequency for all mixtures appeared between temperature 400 and $600^{\circ} \mathrm{C}$. I this temperature range also occurs phase change of $\beta$-quartz to $\alpha$-quartz and decomposition of portlandite (1.2.2). Above the temperature of $600^{\circ} \mathrm{C}$ the rate of decrease in resonance frequency falls. The 
lowest measured frequencies occurred for $1000^{\circ} \mathrm{C}$ temperature sets. Resonance frequency for mixture A was $0.67 \mathrm{kHz}$, for mixture $\mathrm{B} 0.63 \mathrm{kHz}$ and for mixture $\mathrm{C} 0.78 \mathrm{kHz}$.

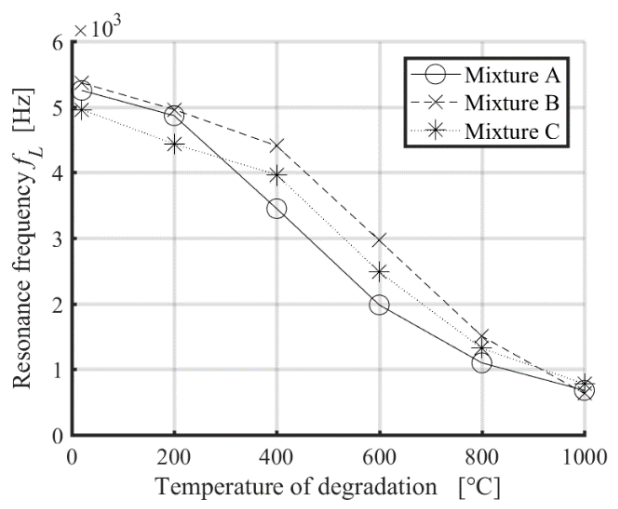

Fig.7. Measurement of longitudinal resonance frequency by IE method.

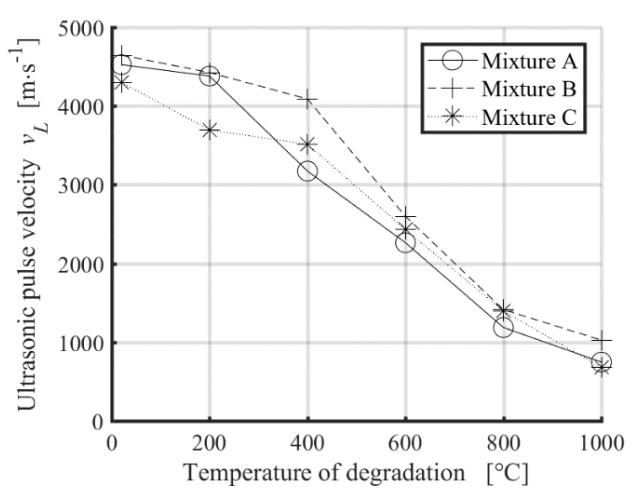

Fig.8. Ultrasounic pulse velocity measurement.

The results of pltrasonic pulse velocity measurement have shown a similar trend in fall of pulse velocity for each temperature sets as is shown on Fig.8. The non degraded mixtures reached velocity from $4350 \mathrm{~m} \cdot \mathrm{s}^{-1}$ to $4620 \mathrm{~m} \cdot \mathrm{s}^{-1}$. A major decrease occured between temperature 400 and $600^{\circ} \mathrm{C}$, which was most significant for mixture $\mathrm{B}$, where pulse velocity change from $4090 \mathrm{~m} \cdot \mathrm{s}^{-1}$ to $2600 \mathrm{~m} \cdot \mathrm{s}^{-1}$. This mixture have shown highest resistance to degradation in term of ultrasonic pulse velocity mesurement. At $1000^{\circ} \mathrm{C}$, the measured value value for mixture $B$ is $1026 \mathrm{~m} \cdot \mathrm{s}^{-1}$, the higher than velocity of mixture A $747 \mathrm{~m} \cdot \mathrm{s}^{-1}$ and mixture $\mathrm{C} 678 \mathrm{~m} \cdot \mathrm{s}^{-1}$. This is quite an oposite result than in the Impact-Echo measurement.

\subsection{Destructive tests}

The results of destructive tests are shown at Fig.9 and Fig.10. For each temperature and reference set a flexural tensile strengthtest and cubic compressive strength test have been conducted. Compressive strength for reference set for mixture A was $66 \mathrm{MPa}$, for mixture B $74 \mathrm{MPa}$ and for mixture C $50 \mathrm{MPa}$.

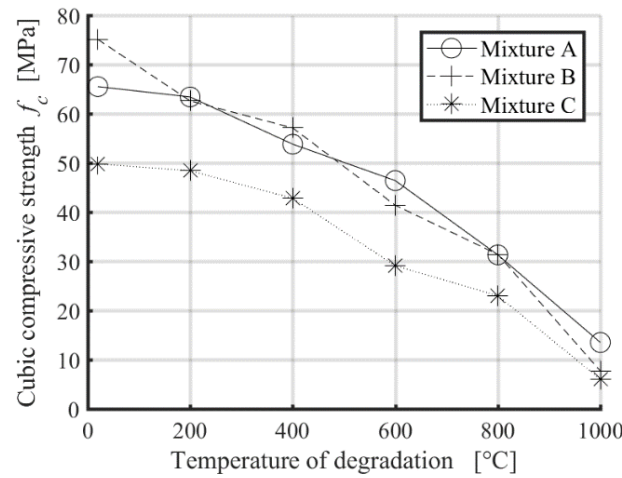

Fig.9. Cubic compressive strength test.

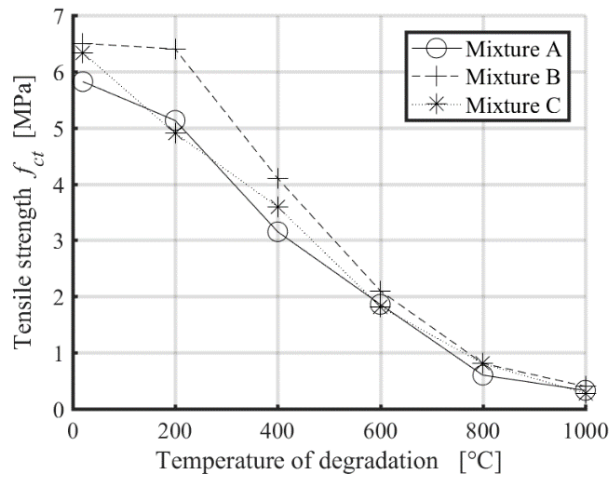

Fig.10. Flexural tensile strength test. 
The first decrease in strength appeared at temperature $200^{\circ} \mathrm{C}$, which was most significant for mixture B, although in Impact-Echo and Ultrasonic pulse velocity measurement this mixture seemed most resistant to temperature degradation.

\subsection{Change in acoustic impedance}

The measured values of density and acoustic velocity in specimens, make it possible to compute acoustic impedance for each temperature set. Fig.11 presentsrelation of acoustic impedance with the change of flexural tensile strength. We can easily recognize, although reference sets show different flexural tensile strength and acoustic impedance, after $40^{\circ} \mathrm{C}$ the measured values match and dispersion of acoustic resistance for 600,800 and $1000^{\circ} \mathrm{C}$ corelate with polynomial trendline of order 2 . The trendline reliability value $\mathrm{R}$ is 0.977 .

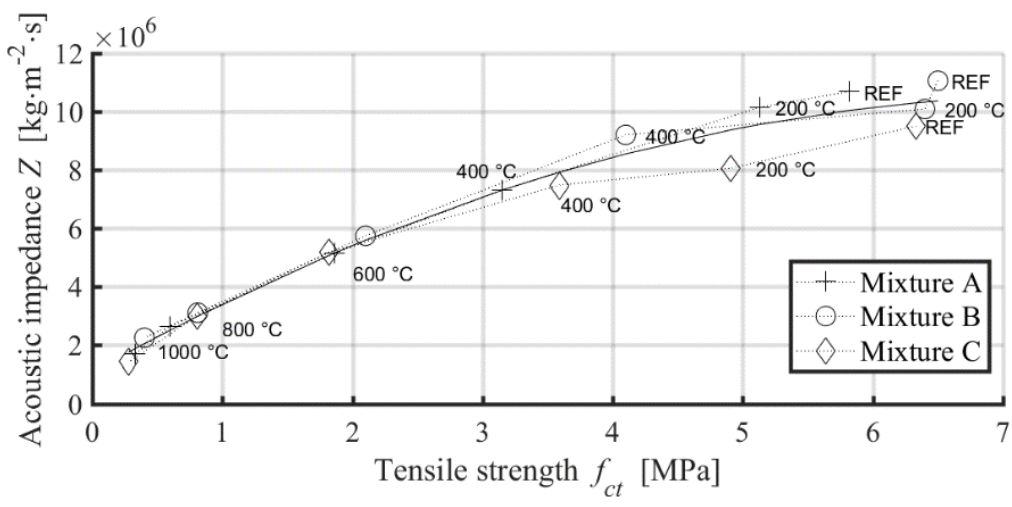

Fig.11. Change of acoustic impedance $\mathrm{Z}$ to flexural tensile strength.

It seems that, at high temperatures, above $400^{\circ} \mathrm{C}$ the rate of acoustic impedance on tensile strength properties of test specimens normalize to narrow values.

\section{Conclusions}

The presented paper aims at non-destructive testing of high temperature degraded concrete test specimens of three mixtures, different by used coarse aggregate. It compares the measured results of 6 temperature sets and 1 reference set for each mixture. A change in measured resonance frequency by impact-echo testing proves a correlation between change of resonance frequency and physical-mechanical state which is represented by destructive tests. Change of acoustic impedance on change of flexural tensile strength is observed. Non-degraded reference sets of all three mixtures have shown different initial values of measured acoustic impedance and tensile strength. At the temperature degraded sets above the $400^{\circ} \mathrm{C}$ the measured values are more intersected by the trend line. From 600 to $1000^{\circ} \mathrm{C}$ reliability $\mathrm{R}$ of a polynomial trendline of order 2 is 0.977 . It seems that the measurement of acoustic impedance for tested degraded specimens may be used as a reliable tool to assessits residual mechanical properties. In the past studies of vibroacoustic methods used on high-temperature degraded concrete has proposed [13]combined application with destructive tests [14]. The approach of the presented paper suggests a process to accurate the condition of thermally degraded concrete via its acoustic impedance obtained from ultrasonic pulse velocity method, or resonance method and the density of concrete. This would be in practice conducted on core bore specimens or insitu. The temperatures during fire accidents in average reach from 400 to $650^{\circ} \mathrm{C}$, these temperatures and the highest ones show a strong dependence between acoustic impedance and tensile strength. This means that most of concrete structures severely damaged by fire, could be assessed by this 
approach. This measurement can be also understood as a possible initial classification of thermally degraded concrete.

This publication was developed under the project No. LO1408 "AdMaS Up - Advanced Materials, Structures and Technologies" supported by Ministry of Education, Youth and Sports under the „National Sustainability Programme I" and under the project GAČR No.16-02261S supported by Czech Science Foundation and under the project FAST-J-18-5275 supported by Faculty of Civil Engineering of VUT.

\section{References}

[1] G.Epasto, E. Proverbio, V. Venturi,Materials and Structures43 (2010)

[2] N.Carino, Proceedings of the 2001 Structures Congress \& Exposition 15 (2001)

[3] V.Malhotra, N. Carino, CRC Press 2 (2004)

[4] A.Savva, , P. Manita, K.K. Sideris, Cement and Concrete Composites27 (2005)

[5] Q. Zhang, Journal of Thermal Analysis and Calorimetry6 (2012)

[6] J. Zhao, J. Zheng, G. Peng, K. V. Breguel,Cement and Concrete Research65 (2014)

[7] ČSN 731371 (1983)

[8] ASTM C1383-15 (2015)

[9] R. Bracewell,The Fourier Transform \& Its Applications3 (USA: McGraw-Hill Science/Engineering/Math, 1999)

[10] ČSN EN 12 390-5. (2009)

[11] ČSN EN 12 390-3 (2009)

[12] ČSN 731316 (1990)

[13]A. Ghorbanpoor, A. Benish, N. Benish,Non-destructive testing of wisconsin highway bridge: Wisconsin highway research program - final report(Wisconsin Department of Transportation, 2003)

[14]K. Krzemien, I. Hager,Construction and Building Materials96 (2015) 